\title{
Desenvolvimento de testemunhador a vibração portátil
}

\author{
Michel Michaelovitch de MAHIQUES; Clodoaldo Vieira TOLENTINO \& Luis Eduardo VILALTA ${ }^{1}$
}

Instituto Oceanográfico da Universidade de São Paulo

(Caixa Postal 9075, 01051 São Paulo, SP)

- Abstract: Vibracoring has been described as an efficient method for the sampling of unconsolidated sediments. In order to improve portability as well as reduce weight, a vibracorer was developed from a brush cutter, with some adaptations. The results show the advantages of the model, even for its use in offshore areas.

- Descriptors: Geological equipment, Sediment samplers, Vibratory corers, Marine geology.

Descritores: Equipamento geológico, Amostradores de sedimentos, Testemunhador a vibração, Geologia marinha.

\section{Introdução}

A testemunhagem por vibração ("vibracoring") tem se mostrado um método eficiente na amostragem de sedimentos inconsolidados de áreas emersas e submersas, com pequena espessura de lâmina de água.

A utilização de modelos de vibradores de concreto para este fim já é largamente difundida, e os resultados conseguidos plenamente satisfatórios (Lanesky et al., 1979; Martin \& Flexor, 1989).

Entretanto, uma das dificuldades encontradas na utilização de vibradores de concreto diz respeito ao peso considerável do equipamento e, conseqüentemente, à sua dificuldade de portabilidade, o que torna penosa a penetraçāo e o trabalho em locais de difícil acesso (Smith, 1987). Dificuldades maiores são encontradas quando da utilizaçāo de vibradores elétricos, por necessitarem de uma fonte de energia (gerador) que, por si, apresenta peso comparável ao do equipamento de vibração. De uma forma geral, apenas o equipamento de vibraçāo necessita do emprego de dois homens para seu transporte, além dos necessários para o restante do material (escada, talha, chicote de vibração) (Lanesky et al., op.cit.).

\section{Uso do motor de roçadeira costal}

Com o intuito de reduzir o peso e facilitar a portabilidade do equipamento, foi desenvolvido um

(1) Haupt São Paulo S/A., Industrial Comercial. testemunhador a vibração a partir de um motor de roçadeira costal.

O equipamento utilizado foi um motor dois tempos, de roçadeira costal "Buldogue", da firma Haupt Sāo Paulo S.A., com potência de $5 \mathrm{HP}$, e algumas adaptaçōes para seu melhor desempenho (Figs 1-2).

O motor é dotado de embreagem centrífuga que, ligada ao acelerador, permite a interrupção da vibração sem desligar o motor, o que facilita a realização de ajustes durante o processo de testemunhagem.

Outra adaptação consistiu na troca do carburador de bóia por outro, de diafragma (Fig. 3), permitindo que o equipamento trabalhe em qualquer posição, o que facilita sua colocaçāo em substratos de qualquer natureza. Foi, também, adaptado o sistema de injeção de gasolina, ligando-o a um tanque de motor de popa (Fig. 4); esta modificação implica em ganho de autonomia do equipamento.

Finalmente, foi desenvolvida uma caixa de redução e inversẫo de rotação, dotada de duas engrenagens helicoidais, alinhadas sobre mancais de rolamentos imersos em óleo. Esta caixa é ligada diretamente ao virabrequim do motor e ao acople do chicote de vibração (Fig. 5). O elemento vibrador trabalha em faixa de 3500 a $5000 \mathrm{rpm}$.

$\mathrm{O}$ conjunto do motor pesa cerca de $13 \mathrm{~kg}$ e sua portabilidade é extremamente facilitada em função de sua estrutura em forma de mochila (Fig. 6).

A utilização do equipamento em áreas emersas segue os mesmos procedimentos adotados com o uso dos aparelhos convencionais, com a utilização de uma escada de sustentaçāo e a tração do testemunho através de uma talha. Em áreas submersas a utilização do equipamento pode ser feita a bordo de embarcaçōes do tipo traineira, chata ou mesmo balsa, sendo necessária apenas a utilização de um guincho ou, eventualmente uma talha para a retirada do testemunho após a cravação. 


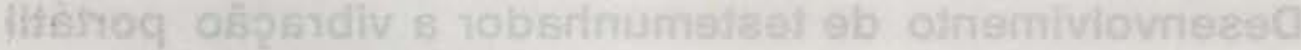

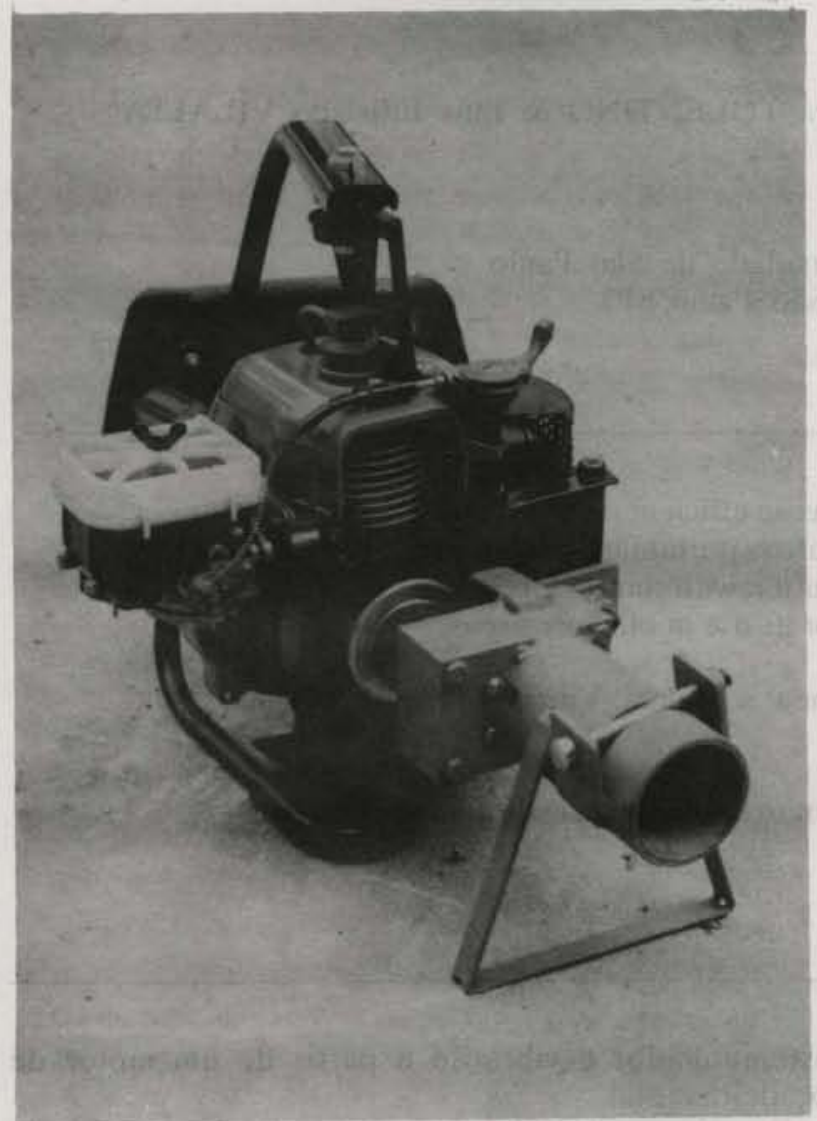

Fig. 1. Vista do motor de roçadeira costal, adaptado para a utilização como testemunhador a vibração ("vibracorer").

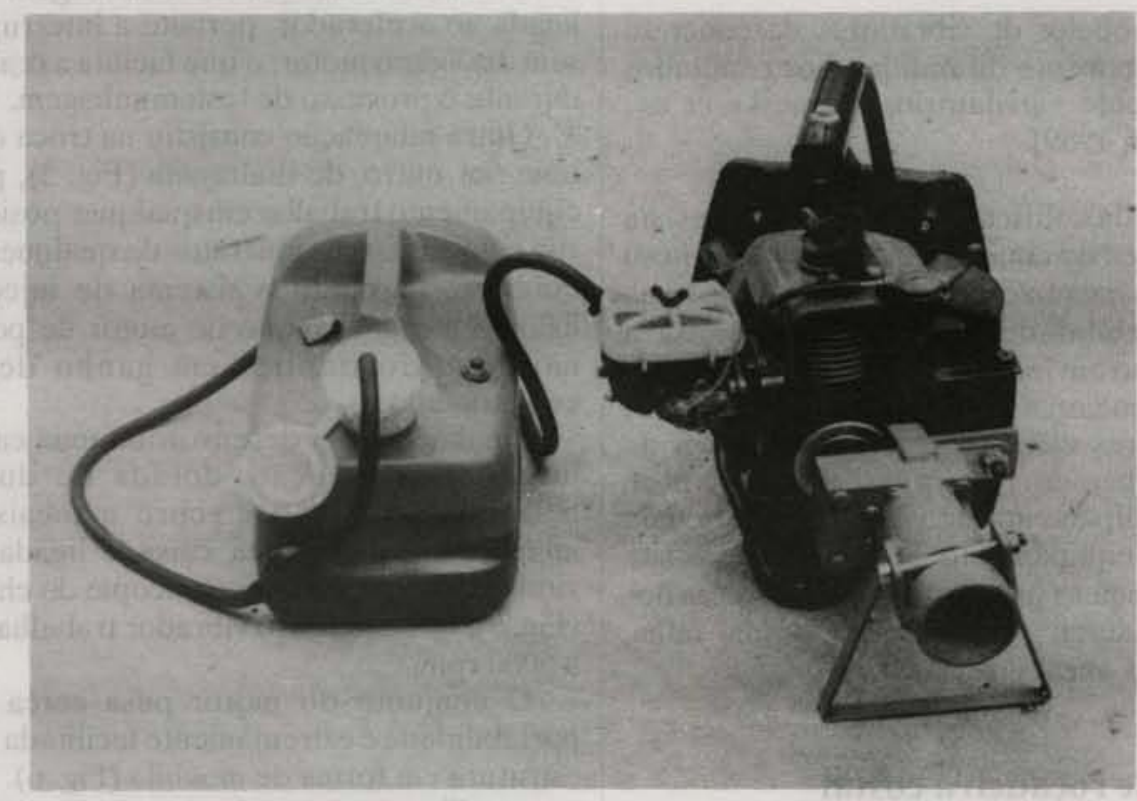

Fig. 2. Vista do motor de roçadeira costal e das adaptaçōes introduzidas. 


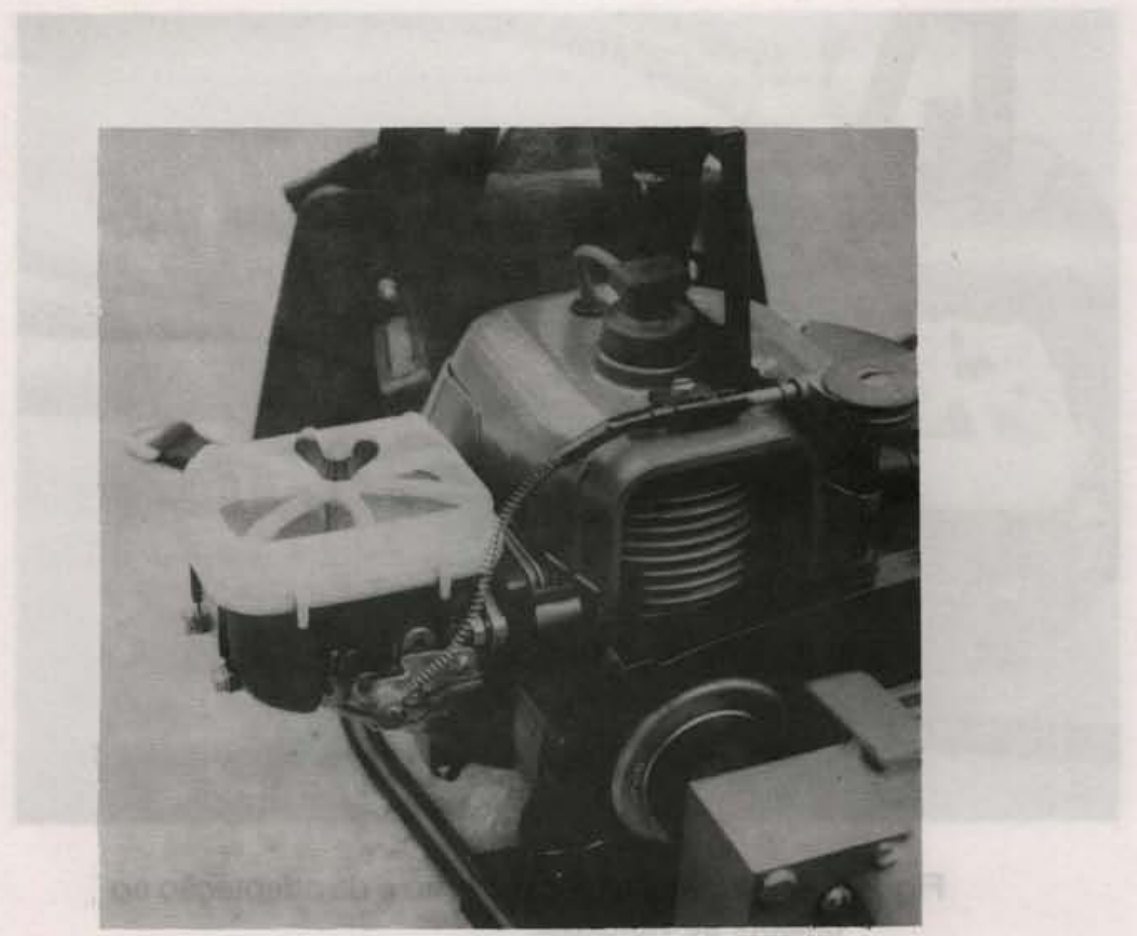

Fig. 3. Detalhe da adaptação do carburador de diafragma.

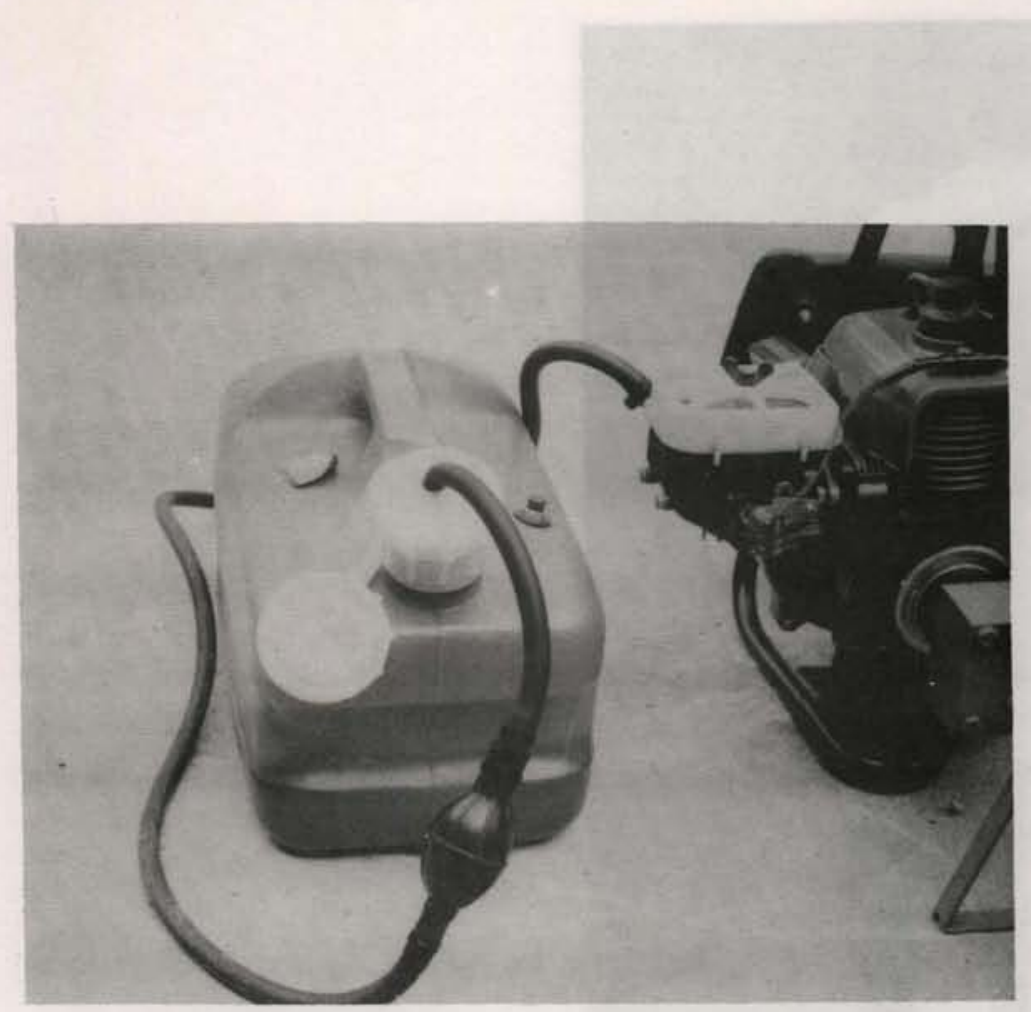

Fig. 4. Detalhe da adaptação do tanque de combustível, acoplado ao sistema de injeção. 


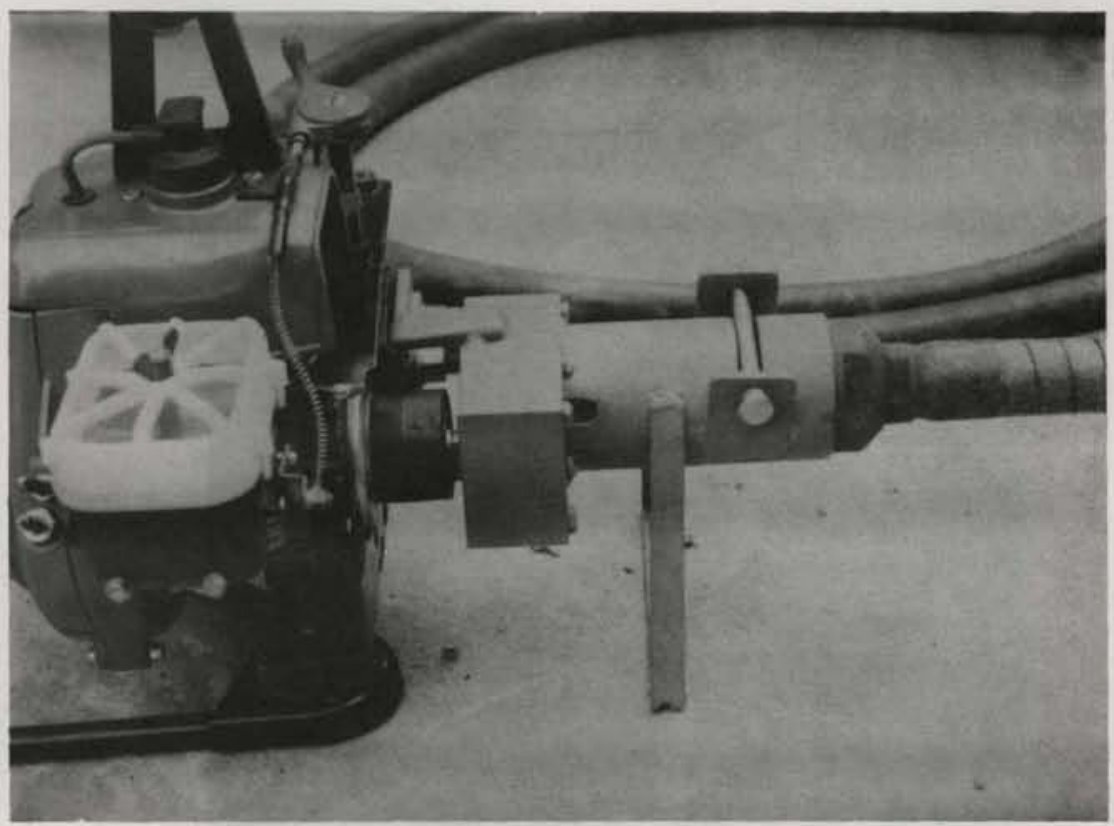

Fig. 5. Detalhe da caixa de reduçäo e da adaptação ao chicote de vibração.

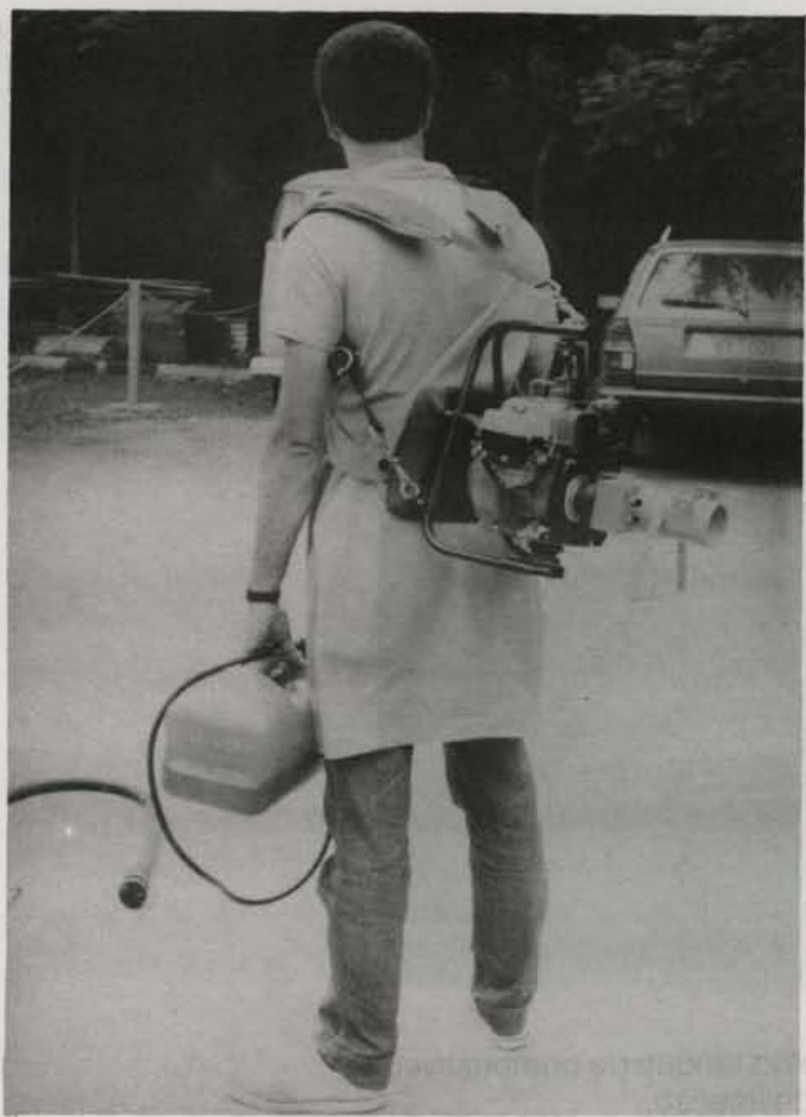

Fig. 6. Detalhe da estrutura em forma de mochila e portabilidade do equipamento de vibração. 


\section{Resultados}

O equipamento foi testado a bordo do B/Pesq. "Veliger II", nas regiōes de Ubatuba e São Sebastiāo, com lâmina de água variável de 3 a $9 \mathrm{~m}$, tendo obtido resultados plenamente satisfatórios, com a obtenção de testemunhos de 3' de diâmetro e comprimentos variáveis de 1 a 4,15 m em fundos essencialmente arenosos a lamosos. Por vezes, o trabalho foi dificultado apenas devido às condições de mar, que nâo permitiam uma cravaçâo perfeita do testemunhador no fundo. Por outro lado, o trabalho em áreas de lâmina de água maior é impossibilitado apenas devido ao pequeno comprimento do chicote de vibração. Cabe observar que, na mesma área, testemunhos obtidos com a utilização de testemunhador a pistão ("piston corer") com cabeçote de $120 \mathrm{~kg}$ de peso e diâmetro de 1,5 , não permitiram a obtenção de testemunhos com recuperação superior a $1,5 \mathrm{~m}$.

A Tabela 1 apresenta as características dos testemunhos obtidos com o equipamento.

Tabela 1. Características dos testemunhos obtidos com o equipamento desenvolvido

\begin{tabular}{llll}
\hline AMOSTRA & $\begin{array}{c}\text { PROFUNDIDADE } \\
(\mathrm{m})\end{array}$ & SEDIMENTO & $\begin{array}{c}\text { PENETRAÇ̄O } \\
(\mathrm{m})\end{array}$ \\
\hline ILT1 & 3 & AREIA & 2,20 \\
ILT2 & 6 & AREIA & 1,00 \\
ILT3 & 9 & AREIA+LAMA & 1,54 \\
ILT4 & 7 & AREIA & 1,37 \\
ILT5 & 8 & AREIA+LAMA & 1,76 \\
UBT1 & 3 & LAMA & 4,15 \\
FLT1 & 4 & LAMA+AREIA & 3,76 \\
FLT2 & 3 & LAMA & 2,45 \\
FLT3 & 3 & LAMA & 1,64 \\
FLT4 & 4 & LAMA+AREIA & 1,84 \\
FRT1 & 3 & AREIA+LAMA & 1,70 \\
FRT2 & 4 & AREIA+LAMA & 1,56 \\
& & & \\
\hline
\end{tabular}

Excelentes resultados foram também obtidos com a utilizaçāo de um "liner" de PVC no interior do tubo de alumínio. Este "liner" consiste de um tubo de PVC branco, fixado às paredes internas do tubo de alumínio através de rebites, de forma que, após a trabalho de testemunhagem, é possível reutilizar o tubo de alumínio, com a simples substituiçāo do "liner" de PVC. Esta facilidade implica numa reduçāo sensível nos custos de uma campanha de testemunhagem.

\section{Conclusões}

A utilização de um motor de roçadeira costal na substituição dos modelos de vibrador de concreto apresenta-se como alternativa de baixo custo, leve e prática para a construçẩo de testemunhadores a vibração ("vibracorers"). As limitaçōes na obtenção de testemunhos de áreas mais profundas devem-se, principalmente, ao comprimento do vibrador (chicote de vibraçāo).

A utilização de um "liner" de PVC no interior do tubo de alumínio permite o reaproveitamento deste último e reduz sensivelmente os custos de testemunhagem.

\section{Resumo}

A testemunhagem por vibração ("vibracoring") tem se mostrado como um método eficaz na amostragem de sedimentos inconsolidados.

Com o intuito de facilitar a portabilidade e reduzir o peso do equipamento, foi desenvolvido um testemunhador a vibração ("vibracorer") a partir de um motor de roçadeira costal adaptado.

Os resultados alcançados demonstram as vantagens do aparelho desenvolvido, mesmo quando de sua utilizaçāo em áreas submersas.

\section{Agradecimentos}

Aos senhores Simon Pablo Juan Erler Von Erlea e Alberto Mahiques Senti, da firma Haupt São Paulo S.A. Industrial Comercial, pelas facilidades concedidas para a confecção do protótipo.

Aos senhores Dr. Moysés Gonsalez Tessler e Dr. Valdenir Veronese Furtado, do Departamento de Oceanografia Física do IOUSP, pelo apoio oferecido.

\section{Referências bibliográficas}

LANESKY, D.E.; LOGAN, B.W.; BROWN, R.G. \& HINE, A.C. 1979. A new approach to portable vibracoring underwater and on land. J. sedim. Petrology, 49(2):654-657.

MARTIN, L. \& FLEXOR, J.M. 1989. Vibro-testemunhador leve: construção, utilizaçāo e possibilidades. In: CONGRESSO DA ASSOCIAÇĀO BRASILEIRA DE ESTUDOS DO QUATERNÁRIO, 2., Rio de Janeiro, 1985. Publicação Especial NN 1. Resumos. Rio de Janeiro, Associaçāo Brasileira de Estudos do Quaternário.. p.1-2.

SMITH, D.G. 1987. A mini-vibracoring system. J. sedim. Petrology, 57(4):757-758.

(Recebido em 13-12-88; aceito em 09-06-89) 